\title{
Neurobehavioural consequences of closed head injury in older adults
}

\author{
F C Goldstein, H S Levin, R M Presley, J Searcy, A R T Colohan, H M Eisenberg, \\ B Jann, L Bertolino-Kusnerik
}

Emory University

School of Medicine,

Atlanta, Georgia, USA

Department of

Neurology

Neurobehavioral

Program) and Wesley

Woods Center

F C Goldstein

R M Presley

Department of

Neurosurgery

A R T Colohan

Department of

Rehabilitation

Medicine

B Jann

Division of

Neurosurgery, The

University of Texas

Medical Branch,

Galveston, Texas,

USA

J Searcy

L Bertolino-Kusnerik

Division of

Neurological Surgery,

University of

Maryland School of

Medicine, Baltimore,

Maryland, USA

H S Levin

H M Eisenberg

Correspondence to:

Dr C Goldstein, Wesley

Woods Health Center, 1841

Clifton Road, NE Atlanta,

Georgia 30329, USA.

Received 1 June 1993

and in revised form

6 September 1993.

Accepted 12 November 1993

\begin{abstract}
This study examined the neurobehavioural effects of closed head injury (CHI) in adults aged 50 years and older. Twenty two mild to moderate CHI patients who were within seven months of the injury were administered measures of language, memory, attention, and executive functioning. Compared with demographically similar normal controls, the patients exhibited significantly poorer functioning on the cognitive domains. Naming and word fluency under timed conditions, verbal and visual memory, and the ability to infer similarities were especially vulnerable. These initial findings indicate that CHI in older adults produces considerable cognitive deficits in the early stages of recovery. Future research should characterise long term outcome and the potential links between head injury and the development of progressive dementia.
\end{abstract}

$(F$ Neurol Neurosurg Psychiatry 1994;57:961-966)

Epidemiological studies reveal a bimodal peak incidence of closed head injury (CHI) in individuals aged 15-24 years and in those $\geqslant 70$ years. ${ }^{1-4}$ Research on the outcome of older adults has employed global measures such as level of independence, length of hospital stay, and discharge disposition. ${ }^{5-8}$ Alberico and colleagues ${ }^{5}$ used the Glasgow outcome scale ${ }^{9}$ to characterise the impact of $\mathrm{CHI}$ on patients up to 80 years of age. They found that the probability of resuming preinjury activities with mild or no neurological deficits declined with advancing age. Pentland $e t a l^{7}$ reported that $86 \%$ of moderately injured patients younger than 65 years of age had good recoveries or required some assistance in the performance of activities of daily living. In contrast, $55 \%$ of moderately injured patients $\geqslant 65$ years were severely disabled or died. Davis and Acton ${ }^{6}$ compared the outcome of severely injured patients who were $\leqslant 25$ years or $>50$ years of age, 2-5 years after discharge from rehabilitation. The second, older group had longer hospital stays, were more dependent in performance of activities of daily living, and were less likely to be working than younger patients.

Apart from these studies of global outcome, little is known about cognitive functioning in older CHI patients. An exception is a recent study $^{10}$ which examined cognitive perfor- mance in patients who were $50-75$ years old at the time of their injuries. Seventy patients were administered tests of general intellectual functioning, memory, language, and visuomotor abilities. Mazzucchi and colleagues ${ }^{10}$ found that $50 \%$ of their patients exhibited generalised deterioration and dementia, whereas only $25 \%$ had minimal or no deterioration. Moreover, patients with mild head injuries, ie, no loss of consciousness, Glasgow coma scale ${ }^{11}$ scores of 13-15, post-traumatic amnesia of <1 day, and normal CT head scans were no more likely to have a better outcome than those with severe injuries. Generalised deterioration and dementia were common in both groups with mild and moderate to severe injury. The study of Mazzucchi et $a l^{10}$ represents an important first step in describing neurobehavioural functioning in the older head injured population. Their research indicates that $\mathrm{CHI}$ produces cognitive deficits across the injury severity spectrum. However, one limitation is that Mazzucchi et al did not examine specific cognitive features, such as memory and language. Instead, they made a gross classification of groups according to impairment on any of these measures. Moreover, their patients were tested from six months to three years after injury. Therefore, early neurobehavioural performance was not characterised.

The present study provided an initial examination of the early neurobehavioural features of individuals who were $\geqslant 50$ years and sustained mild to moderate head injuries. We evaluated abilities which are frequently compromised after CHI in young adults, including expressive language, ${ }^{12}$ memory, ${ }^{13} 14$ attention, ${ }^{15}$ and executive processing. ${ }^{16} \mathrm{We}$ also compared pre- and postinjury living and employment status in a subset of patients.

\section{Methods}

SUBJECTS

Prospective data were collected on 18 men and four women aged $\geqslant 50$ years who sustained mild to moderate CHI. Patients were recruited from acute care hospitals affiliated with the Emory University School of Medicine in Atlanta and the University of Texas Medical Schools in Galveston Houston. Review of medical records and interviews with significant others were conducted to ensure that patients did not have pre-existing or current neurological conditions (for example, cerebrovascular disease, Parkinson's disease, previous head injury), 
and other medical illness (for example, poorly controlled diabetes, cardiac disease, cancer not in remission for two years) which could compromise cognitive functioning. In addition, patients with histories of drug/alcohol abuse, psychiatric disturbance, or learning difficulties were excluded. We also enquired about a decline during the preceding six months in cognitive functioning, personality, and the ability to perform activities of daily living to screen for pre-existing dementia. ${ }^{17}$

Table 1 summarises the demographic characteristics of the patients. Eleven patients were working at the time of their injuries, including three who were $\geqslant 65$ years. Falls produced $50 \%$ of the injuries in our sample, a finding that is consistent with the epidemiological literature on older adults. ${ }^{2371819}$

Sixteen controls who lived in the community were recruited. They were demographically similar to the patients. Identical criteria regarding premorbid and coexisting medical and social conditions were applied in the selection of the controls. Their mean age was $67 \cdot 5$ years (SD 12.5) with an average education of 11.4 years (SD 3.7). Analyses of variance (ANOVA) revealed no significant differences between the groups in age $(F[1,36]=0.08)$ or education $(F[1,36]=$ $1 \cdot 54, \mathrm{p}>0 \cdot 05)$. Fisher's exact tests indicated that the distributions of sex $(p=0 \cdot 70)$ and race $(p=0.37)$ were comparable in the two samples. The mini mental state examination ${ }^{20}$ scores of the controls were within normal limits and ranged from 27 to 30 points (mean $=29 \cdot 6$, SD $0 \cdot 84$ ).

Table 1 also shows the clinical characteristics of the patients, including the interval from

Table 1 Demographic and clinical features of patients

\begin{tabular}{lllllll}
\hline $\begin{array}{l}\text { Age } \\
\text { (years) }\end{array}$ & $\begin{array}{l}\text { Average } \\
\text { education } \\
\text { (years) }\end{array}$ & $\begin{array}{l}\text { Days } \\
\text { after } \\
\text { injury }\end{array}$ & $\begin{array}{l}\text { GCS } \\
\text { score }\end{array}$ & $\begin{array}{l}\text { Cause of } \\
\text { injury* }\end{array}$ & CT findings* \\
\hline Mean & $67 \cdot 8$ & $9 \cdot 7$ & $58 \cdot 2$ & $12 \cdot 8$ & Falls (11) & Normal (8) \\
SD & $12 \cdot 0$ & $4 \cdot 2$ & $61 \cdot 9$ & $1 \cdot 8$ & MVA (7) & SDH (10) \\
Range & $50-87$ & $2-16$ & $5-215$ & $9-15$ & $\begin{array}{l}\text { MVA-Ped (1) } \\
\text { Hit by bike (1) } \\
\text { Assault (1) }\end{array}$ & $\begin{array}{l}\text { SAH (3) } \\
\text { Contusion (1) }\end{array}$ \\
& & & & & Construction (1) \\
\hline
\end{tabular}

«Numbers in parentheses indicate sample size.

MVA = motor vehicle accident; MVA-Ped = motor vehicle accident-pedestrian; GCS = Glasgow coma scale; SAH = subarachnoid haemorrhage; SDH = subdural haematoma.

Table 2 Data on neuropsychological test scores for patients and controls

\begin{tabular}{|c|c|c|c|c|}
\hline \multirow[b]{2}{*}{ Cognitive domain } & \multicolumn{2}{|c|}{ Patients } & \multicolumn{2}{|c|}{ Controls } \\
\hline & Mean & $S D$ & Mean & $S D$ \\
\hline $\begin{array}{l}\text { I Language } \\
\text { Visual naming (points out of maximum of } 60 \text { ) } \\
\text { COWA (total words for three letters) }\end{array}$ & $\begin{array}{l}44 \cdot 2 \\
17 \cdot 1\end{array}$ & $\begin{array}{l}11.2 \\
10.3\end{array}$ & $\begin{array}{l}54 \cdot 8 \\
33 \cdot 1\end{array}$ & $\begin{array}{r}9.9 \\
14 \cdot 2\end{array}$ \\
\hline $\begin{array}{l}\text { II Memory } \\
\text { CRM (correct responses out of maximum of 100) } \\
\text { CVLT (percentage words recalled for five trials) }\end{array}$ & $\begin{array}{l}77 \cdot 3 \\
50 \cdot 0\end{array}$ & $\begin{array}{r}9 \cdot 2 \\
18 \cdot 4\end{array}$ & $\begin{array}{l}84 \cdot 8 \\
69 \cdot 6\end{array}$ & $\begin{array}{r}8 \cdot 7 \\
16 \cdot 7\end{array}$ \\
\hline $\begin{array}{l}\text { III Attention } \\
\text { Alphabet (seconds) } \\
\text { Months (seconds) } \\
\text { Serial threes (seconds) } \\
\text { Months backwards (seconds) }\end{array}$ & $\begin{array}{l}11 \cdot 5 \\
11 \cdot 1 \\
29 \cdot 0 \\
29 \cdot 2\end{array}$ & $\begin{array}{l}13 \cdot 0 \\
10 \cdot 0 \\
18 \cdot 5 \\
18 \cdot 6\end{array}$ & $\begin{array}{r}8 \cdot 6 \\
5 \cdot 4 \\
18 \cdot 5 \\
19 \cdot 1\end{array}$ & $\begin{array}{r}12 \cdot 7 \\
3 \cdot 1 \\
10 \cdot 3 \\
15 \cdot 4\end{array}$ \\
\hline $\begin{array}{l}\text { IV Executive functions } \\
\text { Modified card sort (categories out of maximum of } 6 \text { ) } \\
\text { Similarities (points out of maximum of } 28 \text { ) }\end{array}$ & $\begin{array}{r}2.7 \\
10.0\end{array}$ & $\begin{array}{l}2 \cdot 1 \\
6 \cdot 4\end{array}$ & $\begin{array}{r}4 \cdot 3 \\
17 \cdot 4\end{array}$ & $\begin{array}{l}1.9 \\
7.7\end{array}$ \\
\hline
\end{tabular}

injury to examination. Six patients sustained mild head injuries defined as a lowest recorded Glasgow coma scale ${ }^{11}$ (GCS) score of 13-15, a normal neurological examination, and a normal CT scan. The remaining 16 patients had moderate injuries based on lowest GCS scores of 9-12 or 13-15 when associated with CT findings of a brain lesion (for example, contusion). Six patients underwent neurosurgery for evacuation of subdural haematomas, two of whom were initially sent home from the emergency room but returned days or weeks later as a result of a decline in mental status. One patient fell and was taken to a hospital four days later because of increasing confusion. Galveston orientation and amnesia test ${ }^{21}$ scores were $\geqslant 75$ points (mean $=89 \cdot 7, \mathrm{SD} 8.8$ ) in all patients at the time of testing, signifying the resolution of post-traumatic amnesia.

\section{PROCEDURES}

Neurobehavioural functions were examined that are frequently compromised in young adults. Language was measured by asking patients and controls to name pictured items (visual naming) and to generate words beginning with different letters under a 60 second limit (controlled oral word association) on the multilingual aphasia examination. ${ }^{22}$ Memory was assessed via a shortened dementia version of the California verbal learning test (CVLT). ${ }^{2324}$ Individuals learned and recalled nine words belonging to three categories that were presented over five trials. For visual recognition memory (continuous recognition memory test), ${ }^{25}$ subjects were shown 20 different line drawings of common objects, and they identified 100 additional drawings as old (previously seen) or new (never encountered). Attention and information processing speed were evaluated by having patients and controls perform automatized behaviours, such as reciting the alphabet and the months of the year, as well as activities requiring more effort and involving counting by threes and reversing the order of the months. ${ }^{26}$ Finally, we assessed executive processing based on the ability to infer relationships between items on the similarities sub-test of the Wechsler adult intelligence scale-revised (WAIS-R) ${ }^{27}$ and to generate hypotheses and shift response sets on the modified card sorting test. ${ }^{28}$

\section{Results}

NEUROBEHAVIORAL FUNCTIONING

Multivariate analyses of variance (MANOVAs) were performed separately on the cognitive domains of language, memory, attention, and executive processing using the raw scores obtained by patients and controls. Table 2 shows the means (and standard deviations) for the groups on each neuropsychological test. Group (CHI, control) and centre (Atlanta, Galveston/Houston) were betweensubject variables. Centre was included to evaluate potential differences between the Atlanta and Galveston/Houston samples on the neuropsychological measures. 


\section{Language}

A 2 (group) $\times 2$ (centre) MANOVA examined naming (the number of points for correctly naming pictures) and fluency (the number of correct words provided for three letters). Four patients did not receive the naming procedure, reducing the patient sample size for this analysis to 18 . The MANOVA revealed a significant main effect of group $(F[2,29]=$ $7 \cdot 21, \mathrm{p}<0.01)$, but no main effect of centre $(F[2,29]=0.64, \mathrm{p}>0.05)$ or interaction of group and centre $(F[2,29]=0.46, \mathrm{p}>$ $0 \cdot 05)$. One-way ANOVAs, indicated significant group differences on both tests. As shown in table 2 , controls more accurately named pictures $(F[1,30]=7 \cdot 14, \mathrm{p}<0.05)$ and they also generated a greater number of words beginning with specified letters $(F[1$, $30]=12.00, \mathrm{p}<0.01)$. On this last task, patients exhibited a significantly $(p<0.01)$ higher proportion of non-perseverative errors, such as providing proper nouns (patients: mean $=0.19$, $\mathrm{SD} 0 \cdot 21 ;$ controls: mean $=$ $0.03, \mathrm{SD} 0.06$ ). In contrast, the proportion of perseverative errors, such as repeating earlier items or varying them only slightly (for example, "find" and "finding"), did not significantly differ between the groups (patients: mean $=0.04$, SD 0.07; controls: mean $=$ $0 \cdot 05$, SD 0.05).

\section{Memory}

A 2 (group) $\times 2$ (centre) MANOVA for the memory domain was performed on the number of correct identifications on the continuous recognition memory test and the percentage of total words recalled on the five trials of the CVLT. This analysis indicated a significant difference between patients and controls: $F[2,33]=5 \cdot 49, \mathrm{p}<0.01$. As shown in table 2 , controls recognised more pictures: $F$ $[1,34]=5.46, p<0.05$. Moreover, the percentage of total words recalled on the CVLT was higher for controls: $F[1,34]=9 \cdot 15, \mathrm{p}<$ 0.01 . The main effect of centre $(F[2,33]=$ $0.34)$ and the interaction of group and centre $(F[2,33]=1.65)$ were non-significant.

We examined the learning curves over the five trials of the CVLT to characterise the pattern and rate of improvement. A 2 (group) $\times 5$ (trials) repeated measures ANOVA revealed significant $(p<0.01)$ main effects of group

Mean percentage recall on each of the five trials of the CVLT for patients and controls: $\square$, closed head injury $(n=22)$; $\mathbf{Q}$, controls $(n=16)$.
$(F[1,36]=11 \cdot 31)$, and trials $(F[4,144]=$ $16 \cdot 20)$. Figure 1 displays the mean percentage of words recalled on each trial of the CVLT for patients and controls. Bonferroni corrected, post hoc analyses ( $\mathrm{p}<0.01)$ demonstrated that controls recalled significantly more words than patients on trials 3,4 , and 5 . The interaction of group and trials was nonsignificant $(F[4,144]=0.57)$, revealing that patients and controls exhibited similar learning curves. The greatest increments in learning for both groups occurred between trials 1 and 2.

\section{Attention}

Automatised processing was evaluated by analysing the number of seconds required by patients and controls to say the alphabet and the months. A 2 (group) $\times 2$ (centre) MANOVA was not significant for group ( $F$ $[2,32]=2 \cdot 20)$, centre $(F[2,32]=0 \cdot 14)$, or their interaction $(F[2,32]=0.67, \mathrm{p}>0.05)$. Similarly, a MANOVA on the number of seconds necessary to perform activities requiring more effort, involving counting by threes and reversing the months, was not significant (group: $F[2,25]=2 \cdot 04$; centre: $F[2$, 25] $=1.05$; interaction: $F[2,25]=0.89$, $\mathrm{p}>0.05)$.

These analyses undoubtedly overestimated the capabilities of the patients because they only included individuals who could perform the tasks. Qualitatively, there was a disparity in the difficulty level of the two types of attentional measures. Inspection of the data revealed that 21 of the 22 patients and all of the 16 controls could recite the alphabet/ months. In contrast, seven patients versus one control could not count by threes/reverse the order of the months. Fisher's exact tests indicated non-significant differences $(p=1.00)$ in the distributions of patients and controls able to perform the automatic tasks. Differences in the distributions approached $(p=0 \cdot 11)$ but missed significance for the tasks requiring more effort.

\section{Executive functions}

The executive processing domain examined the number of categories achieved on the modified card sorting test (MCST) and the maximum points achieved on the similarities sub-test of the WAIS-R. Two patients did not receive the card sorting procedure and therefore were not included in subsequent analyses. A 2 (group) $\times 2$ (centre) MANOVA revealed a significant main effect of group ( $F$ $[2,31]=3.97, \mathrm{p}<0.05)$, whereas the main effect of centre $(F[2,31]=2 \cdot 76)$ and the interaction of group and centre $(F[2,31]=$ 0.98 ) were not significant. Univariate analyses demonstrated that patients and controls differed on the similarities sub-test $(F[1,32]=$ $8 \cdot 15, \mathrm{p}<0 \cdot 01)$. As seen in table 2 , controls functioned at a higher level in the ability to infer conceptual relationships between items. Although controls achieved a larger number of categories on the MCST, this difference missed significance $(F[1,32]=3 \cdot 46$, $\mathrm{p}=0.07)$. 
DISCHARGE DISPOSITION AND EMPLOYMENT STATUS

In addition to cognitive functioning, we examined discharge disposition and employment status in our sample. All of the 22 patients were living in non-institutional settings before injury. One patient died and three went on to more supervised environments, that is, personal care or nursing homes, after hospital discharge. These three patients were over 70 years and sustained moderate injuries. They lived alone before injury and did not have spouses to care for them. Eleven patients were working before injury, and six resumed employment after their accidents. There did not appear to be a difference in severity or an associated physical injury between those who did (two milds, four moderates) and those who did not return (one mild, four moderates) to work.

\section{Discussion}

Our findings indicate that mild to moderate $\mathrm{CHI}$ in older adults produces cognitive deficits involving the same neurobehavioural areas affected in young survivors, such as expressive language, memory, and reasoning. Consistent with Mazzucchi and colleagues, ${ }^{10}$ we observed a high frequency of impairments in over two thirds of the sample, a finding also in line with studies documenting the high incidence during the first three months after mild to moderate head injuries in young adults. ${ }^{1429}$ Caution must be exercised, however, in concluding that older adults necessarily have a poor outcome. As 19 of the 22 patients were tested within three months of injury, our findings characterise the initial stage of recovery and do not address long term functioning. It is conceivable that a number of patients will exhibit improvement. Furthermore, our comparison group consisted of controls living in the community as opposed to hospitalised, non-head injured controls. Future research should employ a control group, such as hospitalised orthopaedic patients, for better isolation of the neurobehavioural effects of head injury versus the stresses associated with an acute illness.

The neurobehavioural consequences of head injury in older adults have been vastly understudied in comparison to those in young survivors. Research is limited to general categories such as mortality, length of hospitalisation, and discharge disposition. There is a rise in head injury mortality ${ }^{1830-32}$ and length of hospitalisation ${ }^{78}$ with increased age. Although these findings imply a poor outcome for the elderly, factors which frequently affect their recovery include associated medical conditions involving pulmonary or infectious disorders, cognitive status such as pre-existing dementia, and neurosurgical complications. Roy and colleagues ${ }^{8}$ found that a larger percentage of patients aged $\geqslant 65$ years sustained intracranial haematomas than younger patients. Both groups were similar in overall severity of injury (mild and moderate). Psychosocial supports such as whether a spouse is available to take care of the patient can also have an impact on discharge disposition. Older individuals may not be able to return home because of a lack of assistance. Unlike younger patients who can be discharged to rehabilitation programmes, there are few services available for those over 50 years of age. In essence, the hospital may become a temporary residence until some other means of supervision becomes available.

These considerations highlight the need for detailed investigations of the neurobehavioural effects of head injury in older patients, as well as the delineation of similarities and differences from young adults. Our data reflect a pattern for moderately injured older patients to be at risk of delayed neurosurgical complications. Two individuals with initially high GCS scores of 13-15 were sent home from the hospital, whereas one patient did not seek immediate treatment. These individuals later became confused, and CT/MRI scans indicated haematomas. In contrast to injuries from motor vehicle accidents in young adults, falls are a leading cause of $\mathrm{CHI}$ in patients $\geqslant 60$ years. $^{2371819}$ There is some evidence that falls produce a higher proportion of mass lesions as opposed to diffuse injuries from motor vehicle accidents. ${ }^{5}$ The older individual sustaining $\mathrm{CHI}$ may require a different set of hospital workup, admission criteria, and management techniques than those currently applied to younger people. In addition, the classification of "mild" head injury in a young person may represent a moderate injury in an older one. Neurobehavioural data on acutely injured patients will allow determination of whether these classification schemes using the $\mathrm{GCS}^{11}$ are meaningful and prognostically useful.

In addition to studies focusing on the initial effects of head injury, research should examine recovery patterns in older survivors and whether a subset is at risk of developing degenerative dementia. Epidemiological studies suggest an association between head injury sustained early in life and the later manifestation of Alzheimer's disease. ${ }^{33-35}$ Heyman et $a^{34}$ compared the environmental, medical, and social history of 40 patients who developed dementia before the age of 70 , and 80 community control subjects. A history of severe head trauma was present in $15 \%$ of the index cases as compared to $3.8 \%$ of the controls. Graves et $a l^{33}$ noted that the risk of developing Alzheimer's disease diminished as a function of the postinjury interval. Recently, Mortimer and colleagues ${ }^{35}$ conducted a metaanalysis of 11 case-control studies and found a significant association between head trauma resulting in loss of consciousness and Alzheimer's disease. Postulations of the mechanism underlying post-traumatic dementia include the role of neurotrauma as a provocative or permissive event ${ }^{36}$ and the effects of breaking the blood-brain barrier. Using an experimental rodent model of head trauma, Nilsson $e t a l^{37}$ found that extracellular fluid concentrations of energy-related metabolites (for example, glutamate) were increased as a 
function of head injury severity. Marked increases in excitatory neurotransmitters released at the time of trauma have been implicated in the aetiology of neurodegenerative diseases. ${ }^{38}$ Roberts and colleagues ${ }^{39}$ carried out brain necropsies on 16 head trauma patients who died within 10-18 days of injury and found excessive $\beta A 4$ amyloid protein deposits, a neuropathological feature of Alzheimer's disease, in six individuals who were $45-63$ years old. They argued that it was unlikely that their sample had pre-existing Alzheimer's disease because the prevalence rate is less than $0.01 \%$ in people under 65 years of age. Although intriguing, these studies have been based on either retrospective case methodology or neuropathological studies with no concurrent clinical correlation. The prospective study of head injury in those older adults who are carefully screened for coexisting dementia allows a unique opportunity to identify those who exhibit progressive deterioration in neurobehavioural status.

Another area for future research is the establishment of clinicoanatomical relationships in elderly patients sustaining head injuries, particularly the association between frontal lobe lesions and impairments in neurobehavioural functioning. Neuropathological studies of fatal non-missile head injuries indicate that the frontal lobe is the most frequent site of focal lesions. ${ }^{40}$ MRI of consecutive patients hospitalised for mild to moderate TBI has also shown that the frontal lobe is the most common location for focal areas of increased intensity on T2 weighted scans. ${ }^{1429}$ The ability to exhibit productive thought and to use feedback to generate hypotheses and shift strategy is an important component of cognitive functioning after head injury. Levin et $a l^{41}$ found that disturbances encompassing self-appraisal (for example, an exaggerated self-opinion, overrating ability in comparison with family and clinicians), and planning (poor formulation of future goals) were especially common in patients with severe injuries (GCS $\leqslant 8$ ) but also occurred across the spectrum. These cognitive and personality deficits result from frontal lobe damage in other neurological populations. ${ }^{42}$ The generality of a "frontal lobe" syndrome and the sensitivity of tests to focal frontal lobe damage in older patients still need to be established. In addition to Alzheimer's disease, the elderly head injured patient may be vulnerable to the development of a dementia of the frontal lobe type. ${ }^{43}{ }^{44}$ Behavioural and personality changes such as social withdrawal, unconcern, and disinhibition are prominent early features of frontal lobe dementia, whereas cognitive deficits occur later. Functional imaging techniques such as positron emission tomography will be particularly beneficial in detecting hypofusion in the frontal and temporal regions, and in correlating these changes with neurobehavioural performance.

This research was supported in part by NIDRR Innovation Grant H133C00097 and Field-Initiated Research Grant H133G30051 as well as NS21889, the Javits Neuroscience Investigator Award. We appreciate the assistance of William
Goldman in testing control subjects and Robin Puitt for graphics.

1 Frankowski RF. Descriptive epidemiologic studies of head injury in the United States: 1974-1984. Adv Psychosom injury in the United Stat

2 Jagger J, Levine JI, Jane JA, Rimel RW. Epidemiological features of head injury in a predominantly rural population. F Trauma 1984;24:40-4

3 Kraus JF, Black MA, Hessol N, et al. The incidence of acute brain injury and serious impairment in a defined population. Am $\mathcal{F}$ Epidemiol 1984;119:186-201.

4 Kraus J. Epidemiology of head injury. In: Cooper PR, ed. Head injury. Baltimore: Williams \& Wilkins 1987:1-19.

5 Alberico AM, Ward JD, Choi SC, Marmarou A, Young HF. Outcome after severe head injury: relationship to mass lesions, diffuse injury, and ICP course in pediatric and adult patients. 7 Neurosurg 1987;67:648-56.

6 Davis CS, Acton P. Treatment of the elderly brain-injured patient: experience in a traumatic brain injury unit. $\mathcal{F} \mathrm{Am}$ patient: experience in a traum

7 Pentland B, Jones PA, Roy CW, Miller JD. Head injury in the elderly. Age Ageing 1986;15:193-202.

8 Roy CW, Pentland B, Miller JD. The causes and consequences of minor head injury in the elderly. Injury 1986; 17:220-3.

9 Jennett B, Bond MR. Assessment of outcome after severe brain damage. Lancet 1975;i:480-4.

10 Mazzucchi A, Cattelani R, Missale G, Gugliotta M Brianti R, Parma M. Head-injured subjects aged over 50 years: correlations between variables of trauma and neuropsychological follow-up. $₹$ Neurol 1992;239:256-60.

11 Teasdale G, Jennett B. Assessment of coma and impaired consciousness: a practical scale. Lancet 1974;ii:81-4.

12 Sarno MT, Levin HS. Speech and language disorders after closed head injury. In: Darby JK, ed. Speech and language evaluation in neurology: Adult disorders. New language evaluation in neurology: Adult disord

13 Goldstein FC, Levin HS, Boake C, Lohrey JH Facilitation of memory performance through induced semantic processing in survivors of severe closed head injury. F Clin Exp Neuropsychol 1990;12:286-300.

14 Levin HS, Amparo EG, Eisenberg HM, et al. Magnetic resonance imaging and computerized tomography in relation to the neurobehavioral sequelae of mild and moderate head injuries. $\mathcal{F}$ Neurosurg 1987;66:706-13.

15 Gronwall D. Cumulative and persisting effects of concussion on attention and cognition. In: Levin HS, Eisenberg HM, Benton AL, eds. Mild head injury. New York: Oxford University Press 1989:153-62.

16 Mattson AJ, Levin HS. Frontal lobe dysfunction following closed head injury: a review of the literature. $\mathcal{F}$ Nerv closed head injury: a review
Ment Dis 1990;178:282-91.

17 Blessed G, Tomlinson BE, Roth $M$. The association between quantitative measures of dementia and of senile between quantitative measures of dementia and of senile
change in the cerebral grey matter of elderly subjects. $\mathrm{Br}$ change in the cerebral grey matter

18 Luerssen TG, Klauber MR, Marshall LF. Outcome from head injury related to patient's age: a longitudinal prospective study of adult and pediatric head injury. f Neurosurg 1988;68:409-16.

19 Wilson JA, Pentland B, Currie CT, Miller JD. The functional effects of head injury in the elderly. Brain Inj 1987;1:183-8.

20 Folstein MF, Folstein SE, McHugh PR. "Mini-mental state": a practical method for grading the cognitive state of patients for the clinician. $\mathcal{F}$ Psychiatr Res 1975;12: of patients

21 Levin HS, O'Donnell VM, Grossman RG. The Galveston Orientation and Amnesia Test: a practical scale to assess
cognition after head injury. $₹$ Nerv Ment Dis 1979;167: cognition

22 Benton AL, Hamsher K deS. Multilingual aphasia examination. Iowa City: University of Iowa 1976.

23 Delis D, Kramer J, Kaplan E. The Califormia verbal learning test. San Antonio: Psychological Corporation 1986.

24 Delis DC, Kramer JH, Kaplan E, Ober BA. The California verbal learning test (dementia version), 1988.

25 Hannay HJ, Levin HS. The continuous recognition memory test. Houston: Neuropsychological Resources 1988.

26 Wechsler D. Wechsler memory scale-revised. San Antonio: The Psychological Corporation 1987.

27 Wechsler D. Wechsler adult intelligence scale-revised. San Antonio: The Psychological Corporation 1981.

28 Nelson $\mathrm{H}$. A modified card sorting test sensitive to frontal lobe defects. Cortex 1976;12:313-24.

29 Levin HS, Williams DH, Eisenberg HM, High WM Jr, Guinto FC Jr. Serial MRI and neurobehavioural findings Guinto FC Jr. Serial MRI and neurobehavioural findings
after mild to moderate closed head injury. $f$ Neurol after mild to moderate closed head
Neurosurg Psychiatry 1992;55:255-62.

30 DeMaria EJ, Kenney PR, Merriam MA, Casanova LA, Gann DS. Survival after trauma in geriatric patients. Ann Surg 1987;206:738-43.

31 Galbraith S. Head injuries in the elderly. BMF 1987;294: 325.

32 Jennett B, Teasdale G. Management of head injuries. Philadelphia: FA Davis Co. 1981

33 Graves AB, White E, Koepsell TD, et al. The association between head trauma and Alzheimer's disease. $A m \mathcal{F}$ Epidemiol 1990;131:491-501.

34 Heyman A, Wilkinson WE, Stafford JA, Helms MJ, Sigmon AH, Weinberg T. Alzheimer's disease: a
study of epidemiological aspects. Ann Neurol 1984;15: 
335-41.

35 Mortimer JA, Van Duijn CM, Chandra V, et al. Head trauma as a risk factor for Alzheimer's disease: a collaborative re-analysis of case-control studies. Int $\mathcal{f}$ Epidemiol 1991;20:S28-35.

36 Rudelli R, Strom JO, Welch PT, Ambler MW. Posttraumatic premature Alzheimer's disease: neurotraumatic premature Alzheimer's disease: neuroArch Neurol 1982;39:570-5.

37 Nilsson P, Hillered L, Pontén U, Ungerstedt U. Changes in cortical extracellular levels of energy-related metabolites cortical extracellular levels of energy-related metabolites
and amino acids following concussive brain injury in rats. $\mathcal{F}$ Cereb Blood Flow Metab 1990;10:631-7.

38 Olney J. Excitotoxin-mediated neuron death in youth and old age. Progr Brain Res 1990;86:37-51.

39 Roberts GW, Gentleman SM, Lynch A, Graham DI. $\beta$ A4 amyloid protein deposition in brain after head trauma. Lancet 1991;338:1422-3.

40 Adams JH, Graham D, Scott G, Parker LS, Doyle D. Brain damage in fatal non-missile head injury. $f$ Clin Pathol 1982;33:1132-45.

41 Levin HS, High WM Jr, Goethe KE, et al. The Neurobehavioural Rating Scale: assessment of the Neurobehavioural Rating Scale: assessment f Neurol Neurosurg Psychiatry 1987;50:183-93.

42 Stuss DT, Benson DF. The frontal lobes. New York: Raven Press 1986.

43 Gustafson L, Brun A, Risberg J. Frontal lobe dementia of non-Alzheimer type. Adv Neurol 1990;51:65-7

44 Miller BL, Cummings J, Villanueva-Meyer J, et al. Frontal lobe degeneration: clinical, neuropsychological, and SPECT characteristics. Neurology 1991;41:1374-82. 